\title{
ORDEN DIVINO Y ORDEN HUMANO: EL TEMA DE LOS ESTADOS EN LA LITERATURA ALJAMIADA. ENTRE ESPAÑA Y EL ISLAM
}

\author{
María Teresa Narváez Córdova*
}

"Como es arriba, es abajo", máxima atribuida a Hermes Trismegisto. La jerarquía social que propone el tema de los estados, junto a sus respectivas obligaciones, constituye un intento de remedar el orden divino, regido por la autoridad máxima, Dios. En muchas ocasiones el asunto de los estados no se limita a abordar las categorías sociales y sus respectivos deberes sino que incluye a menudo disertaciones morales, religiosas e incluso esotérico-místicas, como veremos en este trabajo. Me propongo explorar varios textos aljamia$\operatorname{dos}^{1}$ que dedican pasajes al tema de los estados. En una sociedad híbrida culturalmente, como era la española de los siglos XV y XVI, no debe sorprender que autores musulmanes incorporen en sus obras temas procedentes de la cultura cristiana. Tampoco es de extrañar que los "adapten" a un modelo islámico. Más aún cuando el Islam, sobre todo en sus comienzos, unía la autoridad política con la religiosa en la figura del califa ${ }^{2}$.

Vicente Serverat, en su estudio La pourpre et la glèbe. Rhétorique des états de la societé dans l'Espagne médiévale señala que de manera simultánea aparecen en el siglo XIV confesiones rimadas y manuales de confesión. En ambos gé-

\footnotetext{
* Universidad de Puerto Rico.

1. Se trata de textos redactados en lengua romance (castellano, en este caso), utilizando caracteres árabes. Es una escritura a menudo entreverada de vocablos árabes ydialectalismos (principalmente aragonesismos). Estos manuscritos se hacen clandestinos a partir del siglo XVI cuando en España se prohíbe el árabe hablado y escrito. Su temática es muy variada: traducciones de pasajes del Corán con sus comentarios, ritual y jurisprudencia islámicas, relatos de personajes coránicos, consejos, recetas médicas, conjuros mágicos, obras de astrología, técnicas de adivinación e interpretación de sueños, itinerarios de viaje, cuentas comerciales, anotaciones personales y poesía religiosa, entre otros.
}

2. Patricia CRONE y Martin Hinds, God'a Caliph. Religious Authority in the First Centuries of Islam, Cambridge, London, New York, New Rochelle, Melbourne, Sydney, Cambridge University Press, 2003.

3. Grenoble, Université Stendhal, ELLUG, 1997. 
neros, y en grados diferentes, aparece el asunto de los "estados". La sociedad medieval se concibe a imagen y semejanza de Dios: uno y tres en una armonía Trinitaria. Don Juan Manuel (1282-1348) en su Libro de los Estados ${ }^{4}$ divide los tres niveles básicos o estamentos en: "defensores", "oradores" y "labradores", indica José R. Araluce Cuenca (El Libro de los Estados de don Juan Manuel y la sociedad de su tiempo). Luego don Juan Manuel se contradice al señalar que los estados son tantos que no se pueden nombrar todos. Araluce Cuenca opina que el autor parece confundir entre "estado" y el "oficio" que se desempeña dentro de la comunidad. En todo caso, su enfoque ante el asunto es de carácter moral. Para don Juan Manuel conformarse con su estado traerá la felicidad humana y asegurará la vida eterna. Así, apunta Araluce Cuenca, su lista de niveles sociales no es social, alude a los diversos estamentos y oficios de manera secundaria "no para mostrarnos el desarrollo jerárquico de su mundo, sino para mostrarnos cómo y de qué manera podemos alcanzar el fin para el que hemos sido traídos a este mundo: la salvación del alma" (p. 43).

En el siglo XV se establece una jerarquía social compuesta de doce elementos. Así aparecen en Enrique, marqués de Villena (1384-1434), en Los doce trabajos de Hércules ${ }^{5}$, en Pero Guillén de Segovia (1413-1475) en sus «Metros sobre los doce estados» ${ }^{6}$ y en el muftí (jurisconsulto) y alfaquí de la aljama de Segovia, Yça Gidelli (o Iça de Gebir) en su "Suma de principales mandamientos y devedamientos de nuestra santa ley y sunna [tradición]" (1462) ${ }^{7}$. Serverat señala que existe una interrelación entre estos tres autores. Realiza un estudio comparativo de los doce "estados" y concluye que Gidelli se diferencia al no considerar el estamento eclesiástico y sustituir las categorías de "príncipe", "prelado" y "caballero" por las de "califa", "muftí" y "caudillo" (jefe militar), respectivamente. Podríamos decir que "islamiza" los "estados". En palabras de Pedro M. Cátedra se trata de una "adaptación para una cultura religiosa distinta" (p. 182)

Enrique de Villena, según Cátedra: “diseña un plan utópico y universalista, en el que la ciencia metódicamente adquirida es compañera de la fortaleza y está al servicio de la 'cosa pública', de lo que se deriva una moralidad también utópica y representada por las varias facetas del semidios Hércules" (ibídem). Establece asimismo la deuda de Pero Guillén con Enrique de Villena. De éste incorpora Guillén el orden de los estados. Asimismo a Guillén "le sirve la obra de Villena para poner límites éticos al mundo en un orden político" (p. 185).

4. Edición de Ian R. Macpherson y Robert Brian Tate, Madrid, Clásicos Castalia, 1991. También consulté: Don Juan Manuel, Libro infinido, Madrid, Cátedra, Letras Hispánicas, 2003.

5. Los doce trabajos de Hércules. Tratado de la lepra. Arte cisoria, Palencia, Simancas, El Parnasillo, 2005.

6. Obra poética, ed. de Carlos Moreno Hernández, Madrid, Fundación Universitaria Española, 1989.

7. «Tratados de legislación musulmana», edición de Pascual de Gayangos, Memorial Histórico Español, Madrid, Real Academia de la Historia, V, 1853, pp. 247-421.

8. «Los doce trabajos de Hércules en el 'Tirant' (Lecturas de la obra de Villena en Castilla y Aragón)», en Actes del Symposium Tirant lo Blanc, Barcelona, Quaderns Crèma, 1993, pp. 171-205. 
Así las cosas, no es de extrañar que autores musulmanes tanto mudéjares (Gidelli) como moriscos (el Mancebo de Arévalo y Baray de Reminyo) se sirvan del tema de los "estados" para exponer su propia visión social, ética y religiosa dentro de un marco islámico. No debe olvidarse que en los primeros tiempos del Islam el poder político y el religioso van indefectiblemente unidos. Mahoma reúne en su persona las categorías de Profeta y de caudillo militar. La umma (comunidad musulmana) era al mismo tiempo una congregación y un Estado ${ }^{9}$. No será sino hasta el siglo IX cuando comience una secularización del orden político. Ya no gobernarán califas (en árabe: khalīfat Allāh, literalmente "diputado de Dios", solían ser también descendientes del Profeta) sino emires, reyes y sultanes. Entonces comenzarán a traducirse del persa literatura de consejos de gobierno, a veces en forma de testamento. Más tarde el Islam producirá sus propios textos en materia político-moral. Entre ellos, destaco a autores como Algace ${ }^{10}$ e Ibn Hazm de Córdoba ${ }^{11}$. No he podido consultar estos textos (el de Ibn Hazm no ha sido traducido del árabe original). Un estudio de estas obras acaso arroje luz sobre otras posibles fuentes de los autores mudéjares y moriscos que exploraré aquí.

De otra parte, no debe perderse de vista que el Islam comprende todo un sistema de vida que incluye lo religioso y lo jurídico. Lo religioso depende principalmente del Corán y de la sunna o tradición, que se basa en testimonios sobre las palabras y acciones del Profeta a través de una cadena de transmisores autorizados que culminan en una fuente directamente relacionada a Mahoma, constituida por alguno de sus seguidores y testigos de su vida. Lo jurídico (la sharīa a), por su parte, depende de la legislación (o figh) íntimamente ligada en muchos casos a testimonios de carácter religioso y moral. Comprende las reglas otorgadas por Alá para gobernar a los hombres en todos los aspectos de su vida, tanto en lo espiritual como en lo secular. Se compone del Corán, del ejemplo del propio Profeta, de la analogía y del consenso de los estudiosos expertos en legislación. Entre los múltiples tratados de legislación

9. Patricia Crone, God's rules. Government and Islam. Six Centuries of Medieval Islamic, Political Thought, New York, Columbia UP, 2004.

10. Célebre filósofo, teólogo y místico persa (1058-1111) considerado un importante pilar en el Islam al intentar conciliar fe y razón. Su obra cumbre es su monumental Ihya' ' Ulūm al-dīn (Revivificación de las ciencias religiosas). Sus numerosas obras tuvieron un impacto considerable en autores medievales europeos. Véase Miguel Asín PALAcios, Algazel. Dogmática, moral, ascética, Zaragoza, Comas Hermanos, 1904; H. LAOUst, La politique de Gazālī. (Fadā'ih al-bātiniyya), Paris, 1970 y L. BINDER, «Al-Ghazālī's Theory of Islamic Government», Muslim World̀, 45, 1955, pp. 229-241.

11. Filósofo y literato (994-1063), autor de El collar de la paloma, uno de sus más conocidos tratados entreverado de poemas. Véase Miguel Asín PALAcios, Abenházam de Córdoba y su Historia crítica de las ideas religiosas, Madrid, 1927-1932, 5 volúmenes (reimpreso en Madrid, Turner, 1984); Anwar G. CHEjNe, Ibn Hazm, Chicago, Kazi, 1982 y la edición de Emilio GarCía Gómez de El collar de la paloma, Madrid, Alianza, 1971. Su tratado político es el Kitāb al-faṣl fi 'l-milal wa'l-ahwā' wa'l-nihal, Cairo, 1317-1321, 5 vols. 
musulmana, he consultado uno de los más importantes: al-Aḥkām al-Sulțāniyya de Al-Mawardi (974-1058) ${ }^{12}$. Para este autor el contenido estrictamente legal es inseparable de las obligaciones éticas y religiosas. Otro texto jurídico que importa resaltar aquí es la Tafri ${ }^{c} a$ de Ibn al-Ǧallāb (siglo X) ${ }^{13}$. Esta obra trata más bien de casuística jurídica y fue considerada de referencia indispensable hasta la Baja Edad Media. Aunque se conservan varias copias en países musulmanes (Marruecos, Argelia, Túnez, Siria, Egipto y Arabia Saudí) además de uno en Gran Bretaña, es en España donde encontramos un mayor número de manuscritos de Al-Tafrì: tres en árabe y cuatro en romance aljamiado. Abboud-Haggar ha establecido sin género de dudas que este texto es también la fuente de las "Leyes de moros", que son en realidad una versión parcial y arbitraria de Al-Tafrī. Su huella perdura en autores moriscos como el Mancebo de Arévalo, a quien abordaré en detalle más adelante. Como dato curioso y posible exploración futura deseo mencionar el caso de Ibn 'Arabī de Murcia (1165-1240), posiblemente el místico más sobresaliente en el Islam. Este redacta un tratado en el que elabora en clave mística las jerarquías sociales, estableciendo una analogía entre el hombre y su alma con el rey y sus súbditos ${ }^{14}$. Una vez más vemos que el Islam no es ajeno al desarrollo literario del asunto de los estados, tanto en forma de tratados jurídico-morales como en obras de carácter simbólico y místico. Con todo, no hemos hallado ningún texto que establezca un listado de categorías sociales tan minucioso como los de don Juan Manuel, Villena y Pero Guillén de Segovia. Incluso sospechamos que puede no existir pues el Islam considera la umma como una comunidad igualitaria. Bajo este punto de vista acaso no incorpore una jerarquización pormenorizada de cada estado como lo vemos en Europa.

Por eso no deja de sorprender que varios tratados islámicos redactados en España incorporen el tema de los estados en forma similar a la de los autores españoles señalados. L.P. Harvey ${ }^{15}$ es el primero en explorar el texto de Gidelli sobre los estados. También destaca que el manuscrito aljamiado Breve compendio de nuestra santa ley y sunna, redactado por el alfaquí Baray de Reminyo y el Mancebo de Arévalo (en adelante, Breve compendio, Dd.9.49 de la Biblioteca de la Universidad de Cambridge) prácticamente copia el pasaje de Gide-

12. Traducido por Wafaa H. WAHBA, The Ordinances of Government, Reading, UK, Garnet Publishing, The Center for Muslim Contribution to Civilization, reeditado en 2006.

13. Editado por Soha ABBoud-HAGGAR, El tratado jurídico de Al-Tafrĩ de Ibn al-Ğallāb. Manuscrito aljamiado de Almonacid de la Sierra (Zaragoza), estudio, glosario y confrontación con el original árabe por..., Zaragoza, Institución "Fernando el Católico", 1999, 2 vols.

14. El Divino gobierno del reino humano y otros tratados, interpretación, introducción y epílogo de Sheij Tosun Bayrak al-Jerrahi al-Halveti, Buenos Aires, Santiago Arcos, El Sereno, 2006.

15. «'The Thirteen Articles of Faith' and 'The Twelve degrees in which the World is Governed': Two Passages in a sixteenth-century Morisco Manuscript and their Antecedents», en F.W. Hodcroft, D.G. Pattison, R.D.F. Pring-Mill y R.W. Truman (eds.), Mediaeval and renaissance Studies in Spain and Portugal in Honour of P.E. Russell, Oxford, The Society for the Study of Mediaeval Languages and Literature, 1981, pp. 15-29. 
$1 \mathrm{li}^{16}$. Deseo hacer constar que he descubierto que otras dos obras del Mancebo de Arévalo también tratan sobre el tema de los estados. Uno es el Sumario de la relación y ejercicio espiritual (en adelante, Sumario, Ms. Res. 245 de la Biblioteca Nacional de Madrid) ${ }^{17}$ y la Tafsira (Junta LXII) ${ }^{18}$. Curiosamente, estas obras no se limitan a reproducir el texto de Gidelli sino que incorporan un comentario muy original en torno a los estados. Incluso en su Tafsira el Mancebo se sirve nada menos que del prólogo de La Celestina (que cita parcialmente al pie de la letra) para apoyar su disertación sobre los estados ${ }^{19}$. Vemos que este tema está bastante difundido entre la población musulmana de España, si bien adaptado al propósito doctrinal islámico de sus autores.

Pero vayamos al origen: Yça de Gidelli. Este alfaquí mudéjar es muy conocido por la colaboración que ofreció a Juan de Segovia (nacido Juan Alfonso González, 1390s-1468), que fue maestro en Salamanca, obispo en Saboya y Palestina, conciliar en Basilea e islamólogo) en su proyecto de elaboración de un Corán trilingüe (texto desaparecido actualmente) ${ }^{20}$. En diciembre de 1455 llega Gidelli a Aitón para reunirse con Juan de Segovia y realizar una copia en árabe del Corán y su traducción al castellano, explicándole a Segovia los pasajes más oscuros del libro sagrado. Juan de Segovia, a su vez, realizó una traducción del castellano al latín que se escribe de modo interlineal a la versión castellana. Además Gidelli le prepara a Segovia un sumario explicativo de cada una de las azoras del Corán y una exposición de los trece artículos de la fe islámica, "pero lo que Segovia juzgaba de mayor utilidad para discutir con los propios musulmanes, era la anotación de los artículos abrogados que el alfaquí había hecho en su traducción. Escribió también para él, aunque de forma compendiada, la vida y genealogía de Mahoma, a más de otros opúsculos referentes al Islam" (Cabanelas, p. 143). No sabemos si estas obras fueron compuestas por él, o acaso meras copias y refundiciones de textos ya existentes. Tras cuatro meses de intenso trabajo, Gidelli regresa a Segovia (estaba recién casado) y en 1462 redacta la obra que nos ocupa: Suma de principales mandamientos y devedamientos de nuestra santa ley y sunna [tradición] (conocida también como Breviario sunní, como la denominaremos en adelante, y Kitab segoviano). Se con-

16. Harvey lo incorpora en su citado artículo.

17. Editado por Gregorio FONSECA ANTUÑA, Sumario de la relación y ejercicio espiritual sacado y declarado por El Mancebo de Arévalo en nuestra lengua castellana, Madrid, Fundación Ramón Menéndez Pidal, 2002.

18. Editado por mí, El Mancebo de Arévalo: Tratado [Tafsira], edición, introducción y notas de María Teresa Narváez Córdova, Madrid, Trotta, 2003.

19. He publicado un estudio de propósito sobre tan inesperada apropiación literaria, «El Mancebo de Arévalo, lector morisco de La Celestina», Bulletin of Hispanis Studies, Liverpool, LXXII, 3, 1995, pp. 255-272. Incluyo como Apéndices los textos completos sobre los estados de Gidelli, el Breve Compendio, el Sumario y la Tafsira.

20. Darío Cabanelas, Juan de Segovia y el problema islámico, edición facsímil. Estudio preliminar por Emilio Molina López y Concepción Castillo Castillo, Archivum, Universidad de Granada, 2007. 
servan seis copias del texto completo: una en caracteres árabes (Escuela de Estudios Árabes CSIC, Madrid), Junta I, y cuatro en caracteres latinos: Junta LX (Biblioteca Nacional de Madrid), 2076 (antes F.138) y 6016 (antes Q.193) en la Biblioteca de la Real Academia de la Historia, 11/9396 (antes S-3) (único texto de Gidelli editado en su totalidad por Pascual de Gayangos) y el recientemente descubierto en el Archivo General de la Nación (México, D.F. ${ }^{21}$. El manuscrito de la Biblioteca Nacional de Madrid 5301 (antes Gg.180) incluye sólo el primer capítulo de la obra de Gidelli.

El pasaje que nos ocupa es el capítulo LX, el último del Breviario sunní y se titula «De la doctrina y grados en quel mundo se rige y gobierna». Estos grados son: "alhalifa" (califa), "muftí" (jurisconsulto o juez de apelación, superior al cadí), caudillo, religioso, ciudadano, mercader, menestral, maestro, discípulo, labrador, baldío y mujer. Para Harvey la fuente de Gidelli son Los doce trabajos de Hércules de Enrique de Villena, adaptados a una sociedad islámica, en sus primeros dos "grados" (p. 23). Es curioso apuntar que a la hora de comentar estos grados, Gidelli altera el orden y coloca a la mujer en el penúltimo y a los baldíos en el último. La explicación de cada uno de estos grados no solo los describe sino que remite al comportamiento recto que redundará en la salvación del alma. En esto no se diferencia de la postura moral que prevalece en sus antecedentes españoles. Lo que sí resulta desconcertante es que este capítulo cierre un tratado de ritual y legislación musulmanas. Según Gerard Wiegers, el más destacado estudioso de Gidelli ${ }^{22}$, esto puede explicarse si tomamos en cuenta la secuencia de los tres últimos capítulos: el LVIII es "De las señales del día del juyiçio y fin deste siglo", el LIX: "Qué cosa es repintençia y como se ha de hazer para que sea buena" y el LX: "De la doctrina y grados en quel mundo se rige y gobierna". Para Wiegers se trata de un intento de revivificar los valores religiosos musulmanes en un contexto mesiánico que sostiene una conversión final de todos al Islam. Creo que otros textos aljamiados que comentaré más adelante pueden apuntar hacia otras posibles interpretaciones para la inclusión de los "estados" dentro de un texto jurídico-religioso musulmán. Me parece que acaso respondan a una situación inmediata de caos y amenaza a la comunidad islámica. Creo que es en este contexto que debe considerarse la insistencia de autores mudéjares y moriscos en una conducta recta y, sobre todo, acorde a los preceptos islámicos como condición para salvar el alma.

De lo que no cabe duda es de la gran difusión que el texto de Gidelli tuvo en épocas posteriores. Como he señalado, se conservan varias copias de su obra. Más aún, y como ha explorado Wiegers, se observa la huella del alfaquí

21. María Judith Feliciano CHAVES, «Yça Gidelli y la Nueva España: un manuscrito del ‘Breviario sunní en el Archivo General de la Nación (México, D.F.)», Aljamía (Boletín de Información Bibliográfica), Universidad de Oviedo, 13, 2001, pp. 48-51.

22. Yça Gidelli (fl. 1450), his antecedents and sucessors. A Historical Study of Islamic Literature in Spanish and Aljamiado, Tesis Doctoral, Universidad de Leiden, 1991. 
segoviano en muchos textos aljamiados posteriores. En lo que toca al tema que nos ocupa, exploremos tres obras que parecen recoger, ampliar y comentar las jerarquías sociales, siempre supeditadas a una lectura ética moral dentro de un marco islámico. Los tres textos son del Mancebo de Arévalo, si bien uno de ellos fue redactado en colaboración con el alfaquí aragonés Baray de Reminyo (no es posible determinar qué pasajes compuso uno y otro, excepto en aquellos que incorporan anécdotas que permiten identificar a su autor). Es el Breve compendio el que sigue más de cerca la disertación de Gidelli. Pero constituye una suerte de amplificatio: añade comentarios para acentuar la disposición y deberes de cada estado. Veamos un ejemplo.

Para Gidelli:

"Baxo del estado y regla del muftí biben los alimes [sabios], letrados, alfaquies, legistas, sabidores, coronistas, predicadores, declaradores, disponedores, administradores, consegeros, logicos, filosofos y todos los otros letrados que an de ser subditos por ley, que cada uno dellos tiene lectura en su grado y arte de ciençia para ordenar y cumplir y determinar de las cosas de justiçia temporal y çelestial, de lo qual ussando sabiamente, cada uno con efecto y claridad de birtud, abrán el bien berdadero" (Gayangos, p. 413).

\section{En el Breve compendio:}

"El segundo grado es el de mufti, que es protector de la ley y sunna, y su juicio es absoluto. Puede sobre crimen de ley castigar, matar y conceder decretos y otras preeminencias de la ley y sunna. Es pilar de nuestro honrado alquren [Corán], así como el alhalifa, bajo del cual estado son los nahues [comentadores del Corán], que estos son los ordenadores, sarḥadores [exegetas] y declaradores del honrado alquren, de donde toman gobierno las cuatro reglas. Los calimes [sabios] son los que sirven mezquitas de aljamas, adelantados para el servicio de Allah, examinados por Malik [Mālik Ibn Anas, jurisconsulto fundador de la escuela maliquita de derecho] y sus tenentarios. No pueden ser oprimidos sino en ciertas cosas extravagantes reservadas al sumo alhalifado, y todos son sujetos al mufti. Bajo de este estado viven todos los alfaquíes, legistas, sabios, cronistas, predicadores, declaradores disponedores, administradores, consejeros, lógicos, filósofos, teólogos y todos los otros letrados que han de ser súbditos por ley, que cada uno dreellos tiene lectura en su grado, y arte de ciencia de ordenar, cumplir y determinar las cosas de la justicia temporal y espiritual, de lo cual, usando cada uno con efecto, claridad y virtud, serán merecedores del bien verdadero, perdurablemente" (véase Harvey, p. 26-27. Advierto que he modernizado todas las transcripciones de aljamiado de las obras del Mancebo de Arévalo para facilitar la comprensión del texto, aunque conservo algunos términos que reproducen el "sabor híbrido" del texto. En ese caso, los defino entre corchetes).

La minuciosidad con que se ofrecen los detalles relativos a este estado en el Breve compendio acaso respondan a que el público lector está menos familiarizado con estas categorías o quizás responda al "estilo literario" del Mancebo de Arévalo, reconocidamente enrevesado.

Merece la pena en este punto ofrecer algunos datos sobre su persona, por ejemplo los que incluye el propio Baray de Reminyo: “Y yo comencé esta obra 
ocho años después de la dicha conversión [se refiere a la de los moriscos de Aragón en 1525, por tanto la fecha del Breve compendio sería 1533], con ayuda de un escolano de buena doctrina, avisado y de largo comentario: era natural de Arévalo...muy experto...en la lectura arábiga, hebrea, griega y latina y en la aljamiada muy ladino" ${ }^{23}$. Su condición de "escolano" parece remitir a su carácter de estudioso, aunque no habría que descartar otras acepciones del vocablo, tales como "sacristán o acólito". El pretendido poliglotismo que Reminyo le adjudica al Mancebo merece un estudio aparte. La obra del Mancebo está entreverada de citas y frases en latín: seguro que éstas le otorgaban a su disertación una autoridad y un aire de erudición que sin duda impresionaría vivamente a sus lectores. Y aunque su manejo del hebreo y del griego es más bien modesto sería extraordinario en el contexto morisco y posiblemente contribuiría no poco a su prestigio dentro de esta comunidad. A instancias de varios sabios, el morisco escolano se da a la tarea de recoger información sobre doctrina y ritual islámico. El Mancebo viaja extensamente por la Península durante la primera mitad del siglo XVI recopilando el saber conservado por la población morisca e incluso criptojudía.

Adelantándose por siglos al periodismo moderno, el joven peregrina por toda España con el fin de adoctrinarse y "entrevistar" -no hay palabra más adecuada que esta- a los sobrevivientes de la caída de Granada. La información que recopila es de una importancia estremecedora, pues nos permite acceder por primera vez al testimonio directo de las víctimas de 1492 y de las minorías clandestinas musulmanas y judías de la España del XVI. Elabora una curiosa teoría que considera a los musulmanes de España como elegidos de Dios que han recibido como castigo a sus pecados y transgresiones la destrucción y dispersión de su comunidad. Confía en que la condena de su pueblo no se prolongue más de 40 años (en abierta referencia a la duración del éxodo de Israel por el desierto). Las fuentes hebraicas que el Mancebo utiliza en este pasaje (al que he dedicado un estudio ${ }^{24}$ para exponer la historia del pueblo hebreo no sorprenden en el contexto de su obra, si bien resultan insólitas en otras obras aljamiadas, basadas casi exclusivamente en textos musulmanes. El Mancebo, en cambio, incorpora en sus escritos las más variadas fuentes, desde Platón y San Pablo (a quienes utiliza para apoyar la condena islámica al vino), hasta el cadí sevillano Abū Bakr Ibn al- ${ }^{\mathrm{C}} \mathrm{Arabi}$, Algacel o Al-Hasan, entre muchos otros ${ }^{25}$.

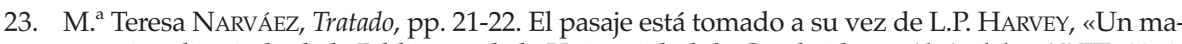
nuscrito aljamiado de la Biblioteca de la Universidad de Cambridge», Al-Andalus, XXIII, 1958, pp. 49-74.

24. «Mitificación de Andalucía como 'nueva Israel': el capítulo 'Kaída del-Andaluzziyya' del Manuscrito aljamiado la Tafçira del Mancebo de Arévalo», Nueva Revista de Filología Hispánica, XXX, 1, 1981, pp. 143-167.

25. Véase María Teresa NARVÁEZ, «Writing without Borders: Textual Hybridity in the Works of the Mancebo de Arévalo», Medieval Encounters. Jewish, Christian and Muslim Culture in Confluence and Dialogue, Vol. 12, n. ${ }^{\circ}$ 1. Edición especial: Interrogating Iberian Frontiers, edición de Barbara F. Weissberger, María Judith Feliciano, Leyla Rouhi y Cynthia Robinson, Leiden, Brill (con la colaboración de la Institución "Fernando el Católico"), 2007, pp. 487-497. 
Incluso parece que nuestro morisco, en su obra Sumario adjudica a figuras musulmanas sentencias que provienen en realidad de la tradición católica y concretamente nada menos que de la Imitación de Cristo de Tomás de Kempis, según ha descubierto Gregorio Fonseca. Sin demasiados escrúpulos de rigor, el Mancebo ha hallado en Kempis un caudal de sentencias ascéticas que sirven perfectamente para su disertación islámica, por lo que las incorpora, adjudicándoselas a prestigiosas figuras del mundo musulmán. Más que una tendencia sincrética religiosa de parte del Mancebo, como propuso en su día Eduardo Saavedra ${ }^{26}$, nos parece más bien que se trata de un esfuerzo encaminado a demostrar que otras tradiciones coinciden en ciertas posturas y actitudes fundamentales en el Islam, una validación y reafirmación de éste. De otra parte, es innegable que nuestro morisco no fue ajeno a la tradición cristiana, hecho explicable dada su condición de escolano. Más aún, recordemos que el Mancebo se comportaría públicamente como católico practicante: sabemos que en cierta ocasión hizo la misma confesión de pecados a diversos sacerdotes, cada uno de los cuales le impuso una penitencia diferente ${ }^{27}$. Esto le convenció del carácter arbitrario de esta práctica sacramental católica. Su obra, de estilo personalísimo, con un vocabulario "horriblemente difícil" (la frase es de Harvey) y un discurso complejo y en ocasiones indescifrable no tiene parangón en el corpus aljamiado. Su disertación incluye doctrina, ritos, jurisprudencia, reglas de convivencia y modales, pasajes esotéricos, refranes y sobre todo innumerables testimonios personales que nos permiten atisbar al variado panorama humano de la España de su tiempo. Con auténticas dotes de "cronista" y autor "costumbrista" describe el físico, la personalidad y la vivienda de muchos de sus "maestros" religiosos. En escenas de gran plasticidad, accedemos a encuentros, enseñanzas, discusiones y, sobre todo, a la nostalgia de un mundo y una cultura en vías de desaparecer ante la represión de las autoridades cristianas.

Pero volvamos al tema de los estados. En el Sumario, su obra más ascética, el Mancebo de Arévalo aborda sólo tres estados: el de califa, el de muftí y lo que él denomina: "estado podiçial" (vocablo que parece asociarse a poderío. Comprobamos que nuestro autor realiza una variante significativa a las categorías tradicionales, incorporando un nuevo estado). Parecería que este "estado podiçial" tiene connotaciones espirituales. Dice el Mancebo:

“Capítulo del estado podiçial. Éste es de los devotos [o ascetas] yotras...personas recogidas y amparadas. De todos los estados, éste es el más feliz para el alma. Dijo Katādatā [tradicionista islámico]: ¡Ah, qué buen perdón....verá quien

26. «Literatura aljamiada. Discurso de recepción en la Real Academia Española, el día 29 de diciembre de 1878», Memorias de la Real Academia Española, Madrid, M. Tello, VI, 1889, pp. 140192 y pp. 237-328.

27. L.P. HARVEY, «El Mancebo de Arévalo y la literatura aljamiada», en Actas del Primer Coloquio Internacional sobre Literatura Aljamiada y Morisca, Madrid, Gredos, Colección de Literatura Española Aljamiado y Morisca (CLEAM), 1978, pp. 21-42. 
dejare la pleitesía del mundo! Dijo 'Umar Bey [personaje no identificado]: Oh, siervos de Allah, yo os consigno al Paraíso a todos los adiestrados de buena intención y obra, aquellos que desdeñaréis el mundo porque la vida es para el otro mundo. Dijo Almurabey [personaje no identificado]: ¡Oh, cómo pasamos los piélagos de esta vida sin hacer acato de lo que habemos de ser, y cómo habemos de pasar por la dormida mayor, y nos han de dar el parabién de nuestro despertar! Plegue a Su Divina Bondad inmensa que nos dé tal perdónque pongamos "açcud" [ampara] para cuando sople Içrafil [Azrael, el ángel que toca la trompeta el Día del Juicio Final] con su trompeta, que dicen los nahues [comentadores del Corán] que hará tan fuerte resoplido que no quedará al'ars [trono] cuyo centro no se estremezca y se mueva y lo que más se removerá será la tierra que pisaron los hijos de Adán. Bien sintió Almurabey lo que dijo, pues el rey de Córdoba lloró toda la luna dulhigante [último mes del calendario musulmás, mes de la Peregrinación a Meca], tan buena para los adoctrinados y salihas [piadosos, ascetas]. A éstos llaman llorosos espirituales, que dan luz con sus hechos" (Cf. Fonseca, Sumario, p. 268. La modernización es mía).

El pasaje parece original, hasta el momento no hemos topado con ninguna fuente de la cual pueda derivarse. El motivo del llanto espiritual sí puede trazarse a Gidelli: "y para que los pecadores sus grandes pecados les sean tornados meritos, llore el largo tiempo que estubo en ellos, con lagrimas de sangre sallidas de su coraçon hasta que muera" ${ }^{28}$. Wiegers señala que las lágrimas del arrepentimiento constituyen un tema místico común entre los sufíes ${ }^{29}$. En efecto, Annemarie Schimmel destaca el elogio de las lágrimas entre ascetas y místicos: éstas "borran" la tinta negra en la que están escritos los pecados ${ }^{30}$. Parecería que algunos ecos del sufismo aún resonaban entre los musulmanes de la España del siglo XV y XVI ${ }^{31}$.

28. Véase P. de GAYANGOS, op. cit., p. 411.

29. P. 138.

30. Mystical Dimensions of Islam, Chapel Hill, North Carolina Press, 1975, pp. 414-415.

31. Este tema ha suscitado gran interés. Incluso llegó a proponerse a los moriscos como posible vínculo entre el sufismo y los místicos cristianos españoles. SAAVEDRA, op. cit.; Miguel Asín PALACIOS, «Un precursor hispanomusulmán de San Juan de la Cruz», Al-Andalus, I, 1933, pp. 779; «El símil de los castillos y moradas en la mística islámica y en Santa Teresa», Al-Andalus, XI, 1946, pp. 263-274; «Sadilies y alumbrados», Al-Andalus, IX-XVI, 1944-1951, estos dos últimos han sido publicados como libro, Sadilies y alumbrados, estudio introductorio de Luce López-Baralt, Madrid, Hiperión, 1990; Álvaro GALMÉS DE FuENTES, «Significado e influencia de los moriscos conversos en el pensamiento heterodoxo en la España cristiana», en Le Ve Centenaire de la Chute de Grenade. 1492-1992. Actes du V Symposium International d'Études Morisques, Abdeljelil Temimi (ed.), CEROMDI, Zaghouan, Tunisie, 1993; Luce LÓPEZ-BARALT y María Teresa NARVÁEZ, «Estudio sobre la religiosidad popular en la literatura aljamiado-morisca del siglo XVI. La Mora de Úbeda, el Mancebo de Arévalo y San Juan de la Cruz», Revista de Dialectología y Tradiciones Populares, XXXVI, 1981, pp. 17-51 y reproducido en Luce LÓPEZ-BARALT, San Juan de la Cruz y el Islam, Madrid, Hiperión, 1990; María Teresa NARVÁEZ, «¿Qué sabían los moriscos sobre misticismo y temas esotéricos?», en Luce López-BARALT y Lorenzo PIERA (eds.), El sol a medianoche. La experiencia mística: tradición y novedad, Madrid, Trotta y Centro Internacional de Estudios Místicos, 1996 y «El despertar y el sueño: dos motivos místicos en un texto 
Merece la pena destacar que el Sumario sólo incluye los tres primeros estados y que todos están relacionados con el Islam. No puedo asegurar que ese fuera el texto original compuesto por el Mancebo: quizás los mencionó a todos en una redacción original y el manuscrito que conservamos es una copia editada. Pero me inclino a pensar que en este caso eligió circunscribirse sólo a tres estados con el fin de "islamizar" su discurso, ignorando deliberadamente el resto de "grados" o jerarquías que serían contrarias, como ya se ha mencionado, al espíritu igualitario de la umma islámica. Acaso su elección apunta a que observa un debilitamiento de la práctica islámica secreta entre sus lectores moriscos y desea fortalecerles en la práctica y fe. Con todo, es obvio que a esta comunidad morisca le sería muy difícil ejercer en la clandestinidad su jerarquía religiosa y jurídica: difícilmente podrían ordenar sus jueces azotes o la muerte o incluso dirigir la oración sus imames. Y si lo hacían sería en el más estricto secreto y con riesgo de sus vidas.

Pero es en la Tafsira donde el Mancebo de Arévalo despliega su ingenio discursivo. En su «Capítulo de los estados» el propósito primordial no es realizar un listado de jerarquías y oficio sino destacar la importancia de desempeñarse recta y virtuosamente. Nuestro morisco advierte a sus lectores que los más altos estados son los más riesgosos para el alma, entrañan mayor peligro de revés espiritual. En su exposición incluso insiste en señalar los aspectos más negativos del mundo. Se sirve para ello de una extensa cita sacada del prólogo de La Celestina (cita que a su vez Fernando de Rojas traduce del De remediis utriusque fortunae de Petrarca) ${ }^{32}$. Creo que para un morisco sometido a las presiones de una sociedad que perseguía a los criptomusulmanes y conversos de judío, propiciando un clima de angustiosa desconfianza, el texto de Petrarca, que ve al mundo como producto de "lid y contienda", describía certeramente su propia realidad. (No olvidemos que Rojas, converso de judío, también se siente impactado por ese mismo pasaje de Petrarca: de seguro reflejaba el entorno en el que le tocó vivir.) No hay que olvidar, de otra parte, que también don Juan Manuel, Villena y muy especialmente Pero Guillén describen los peligros, tentaciones y actos impropios de los miembros de cada estado en sus respectivas sociedades. Su descripción de vicios sirve de base para destacar la importancia y necesidad de sus consejos morales. Pero sólo en la Tafsira del Mancebo de Arévalo vemos incorporada una visión del caos y la con-

aljamiado», en William MejíAs LóPEz (ed. y comp.), Morada de la palabra: homenaje a Luce y Mercedes López-Baralt, San Juan, Editorial de la Universidad de Puerto Rico, 2002, vol. II, pp. 1213-1222, entre otros. Las investigaciones que Luce López-Baralt y yo misma hemos abordado sobre este asunto apuntan hacia un conocimiento ya muy fragmentado e incompleto de motivos y términos esotéricos y místicos entre los autores moriscos.

32. Hemos constatado que el Mancebo cita por Rojas, toda vez que su pasaje es casi idéntico al de éste y se diferencia notablemente de la primera traducción al castellano del texto de Petrarca, realizada por Francisco Madrid y publicado en 1525. Véase, María Teresa NARVÁEZ, «El Mancebo de Arévalo, lector morisco...». 
tienda de dimensiones universales y no meramente humanas. Las imágenes de Petrarca que Rojas traduce y el Mancebo incorpora casi parecen apocalípticas.

Examinemos más de cerca el «Capítulo de los estados» de la Tafsira. El autor comienza haciendo referencia a los deberes $u$ obligaciones del hombre, y a la necesidad de poner a prueba los consejos y discernir los que son verdaderos. Establece un orden de seres a los que el hombre está obligado. Éstos son: su Creador, sus padres, la aljama (comunidad islámica), sus parientes, sus hijos, los pobres, los afligidos y los animales provechosos. Es entonces cuando pondera los peligros del mundo con estas palabras:

“es menester audacia porque el mundo da lo peor de su casa y naturaleza, cría las cosas a manera de contienda y a modo de pleitesía, contrario unos de otros. Y por eso es bueno que cada uno roa las cortezas de los edificantes y de sus dichos tan provechosos, de aquellos que por sus claros ingenios espirituales merecieron ser honrados y aprobados" (pp. 295-296. He modernizado el texto).

En este punto añade la cita del prólogo de La Celestina. Solo cito un fragmento:

"Más dicen: sin lid ni ofensión ninguna cosa engendró la naturaleza que es madre de todas las cosas...que las estrellas se encuentran en el firmamento de los cielos; adversos elementos unos a otros se rompen, estremecen las tierras, ondean las mares, el aire se sacude...Estrellas, peces, aves y los demás terrestes animales, hasta los pensamientos guerrean entre los jaleqados [creados] y discurren las pleitesías y guerras, las artes y los engaños contra los cuerpos y las almas y en toda cosa se parecerá lo mismo" (p. 296).

Ante este panorama desolador, el Mancebo cita a ${ }^{C}$ Umar Bey para destacar la importancia de que cada uno reconozca su estado: rico o pobre, grande o menor. En todos hay posibilidad de salvación para aquellos que poseen buena consciencia. Pero es preciso reconocer que los más altos son los más peligrosos: son los que pueden traer más daño al alma.

Incorpora una anécdota recogida por Katādatā según la cual un judío planeaba asesinar a ${ }^{\mathrm{C} U m a r}$ (el primer califa tras la muerte de Mahoma). Eran tiempos de hambre y escasez y un día 'Umar le obsequia al judío treinta dátiles. El generoso gesto impactó tanto al judío que, arrepentido, lanzó el puñal que llevaba bajo su manto, confesó a 'Umar sus planes y se hizo musulmán. El episodio sirve para ilustrar la importancia de las buenas obras y de los ejemplos virtuosos, incluso hacia quienes consideramos nuestros adversarios. Finalmente, el Mancebo destaca el poder de la conducta recta y piadosa, sea en lo tocante a la ley y sunna, en la guerra, en las relaciones familiares y comerciales. Termina con un hermosísimo pasaje que describe la luz beatífica que alcanzaremos a ver si obramos de acuerdo a las enseñanzas del Corán. Cito sus palabras:

"Dicen los nahues [exegetas] que si descendiese a este alcarsse [trono, en este contexto, plano terrestre] una centella de la claridad de aquella luz beatífica del al'arsse soberano donde Su Bondad manifestó las cosas incomprensibles, que la tal vislumbre no impediría cosa a vuestros ojos por delante ni por detrás, 
tanto con ampara como sin ella, tanto lejos como cerca, tanto lo mínimo como lo grande, ni aunque fuese un átomo a sol saliente y otro a sol poniente. De tal suerte que la luz de nuestros ojos penetraría como la luz del sol de este al'arsse. Dice el honrado Alcorán: Alcanzaréis esta luz, no seáis negligentes, obrad según el Alcorán y habréis luz y descanso y holgura en vuestras almas" (p. 298).

Me parece que en este capítulo el tema de los estados es un mero pretexto para disertar en torno a un mundo caótico y hostil en el cual se hace imperativo mantenerse fiel a la devoción musulmana, si se quiere alcanzar la salvación del alma. No basta obrar con rectitud, es necesario seguir las enseñanzas del Corán para alcanzar ese estado de "iluminación", ese anegarse en la "luz beatífica". No cabe duda de que estamos ante un discurso que recuerda poderosamente al de los místicos. No solo por su insistencia en esa luz que todo lo inunda sino en esa sensación de abarcarlo todo: lo alto y lo bajo, lo lejano y lo cercano, lo oculto y lo manifiesto ${ }^{33}$. Si el pasaje es original del Mancebo de Arévalo, estamos ante un autor con un estilo propio y una auténtica vocación literaria. Como en otros pasajes de su obra, se apropia de textos ajenos (en este caso, Gidelli y Petrarca por vía de Fernando de Rojas) pero no se limita a copiarlos. Los adapta y utiliza como punto de partida para exponer su propio discurso espiritual, siempre orientado hacia una exaltación de las excelencias del Islam. Resulta conmovedor comprobar cómo en tiempos tan "recios" para los moriscos, perseguidos en un denodado intento de asimilación de parte de las autoridades cristianas, un grupo de musulmanes secretos arriesga sus vidas para mantener viva su identidad religiosa. Clandestinamente y sin duda con una red de apoyo amplia, viajan, se reúnen, leen, traducen, copian y redactan textos que hoy son testimonios invaluables de una comunidad en vías de desaparecer. Los textos árabes y aljamiados que nos dejaron, ocultos en pisos falsos, nichos y columnas nos revelan un componente poco conocido de la sociedad y la cultura de la España del Siglo de Oro. Una comunidad secreta que lucha por preservar su identidad legando por escrito y en el alfabeto árabe (sagrado por ser vehículo de la revelación Divina en el Corán) un caudal de creencias, prácticas, relatos, poemas y anécdotas que conforman su concepto del mundo

33. Recordemos los versos extáticos de San Juan de la Cruz en su «Cántico espiritual», que abarcan los elementos (tierra, agua, aire), lo alto y lo bajo, el silencio y el sonido, lo cercano y lo lejano, la noche y el día:

Mi Amado, las montañas

los valles solitarios nemorosos,

las ínsulas extrañas,

los ríos sonorosos,

el silbo de los aires amorosos,

la noche sosegada

en par de los levantes de la aurora,

la música callada,

la soledad sonora,

la cena que recrea y enamora. 
y de la vida. Entre ellos, el joven escolano conocido como el Mancebo de Arévalo aprovecha textos y temas ajenos al Islam y los "islamiza" al emplearlos para su propósito adoctrinador. Los estados son para él vehículo idóneo para insistir en sus estrictas pautas morales islámicas. En una sociedad que pretende relegarlos y hacerlos desaparecer como nación, en un ambiente plagado de lides y contiendas es imperativo recordarles a los lectores moriscos que hay un orden divino y que cada hombre puede remedarlo actuando con rectitud y devoción. Es esto lo que hace el Mancebo de Arévalo, como en su día lo hicieron sus antecesores literarios cristianos y mudéjares.

Los textos aljamiados que aquí hemos comentado dan fe de una sociedad pluricultural. Los moriscos leen los textos cristianos a la par que los islámicos. Ante al enfrentamiento religioso, existe también un cierto acercamiento de intención, si bien por vías distintas. Las comunidades cristiana y musulmana, en medio del desorden y el caos, intentan establecer un orden social y religioso terrestre, que sea reflejo de ese orden perfecto del cielo.

\section{APÉNDICE I}

\section{De la doctrina y grados en quel mundo se rige y gobierna Breviario sunní de Yça Gidelli ${ }^{34}$}

El mundo se rige y gobierna en doze grados. El primero grado es el estado de alhalifa [califa]. El segundo de mufti [jurisconsulto]. El tercero de caudillo. El quarto de religioso. El quinto de ciudadano. El sexto de mercaderes. El séptimo de menestrales. El octabo de maestros. El nobeno de diçipulos. El dezeno de labradores. El onzeno de baldios [ociosos, sin oficio]. El dozeno de mugeres. Cada grado y estado de los quales contiene en sí dibersas costumbres, tratos, ussos, bibiendas y exerçicios. Empero si cada uno ussa de su arte en su tiempo y lugar, segun como debe, acordando y entendiendo sobre su estado y arte, amando á su Criador, tomando solo aquello que fuere suyo, serán dignos de ser loados y bien abenturados, dexando á parte los baldios de quien hize mençion, para en su lugar dar noble exemplo.

El estado y grado de alhalifa, conbiene saber que es adelantado de Allah taale [ensalzado sea ], mayor en la tierra y gobernador justo, en la qual regla y estado biben y deçienden prinçipes, reyes, gobernadores y justiçias: todos los quales arriba dichos son obligados á ebitar yra, cobdiçia y todos los otros biçios, manteniendo y guardando justiçia, tomando sus derechos debidos y serán dignos de gloria perdurable. Baxo del estado y regla del mufti biben los alimes [sabios], letrados, alfaquies [jurisconsultos], legistas, sabidores, coronistas, predicadores, declaradores, disponedores, administradores, consegeros, logicos, filosofos y todos los otros letrados que an de ser subditos por ley, que cada uno dellos tiene lectura en su grado y arte de çiençia para ordenar y cumplir y determinar de las cosas de justiçia tem-

34. Pascual de GAYANGOS, op.cit., pp. 412-416. He definido entre corchetes los vocablos árabes. 
poral y çelestial, de lo qual ussando sabiamente, cada uno con efecto y claridad de birtud, abrán el bien berdadero.

El grado del caudillo es que debaxo de su estado y regla biben todos los capitanes, alcaldes, caballeros y todos los otros hijos de algo y de linage, gentiles hombres que usan y biben de armas y caballerias y todos los otros grados birtuosos á quien perteneçe de exerçitar y multiplicar las birtuossas costumbres, lealtades y franquezas en lo que tienen á cargo de servir y gobernar, á conserbaçion y defensa del bien comun á fin de lo que fueron criados, con lo qual salban sus almas.

Baxo del estado y grado de religiossos bibe todo creyente en el Criador que bibe en regla de la creençia y salud del alma, que es ser birtuoso y bien abenturado en mantener y guardar la ley, abito y comunidad del alchama [reunión de musulmanes], ajuntamiento y ermandad della. Ay unos de mayor religion que otros en quanto son apartados de los biçios, assi como los ayunadores, limosneros y oraçioneros de bida santa, con la qual bibienda son bien abenturados y salban sus almas.

Baxo del grado del ciudadano biben muchos onrrados hombres que no biben de trabajar con sus manos, sino que tienen heredades de que se mantienen; ni tratan, ni son conoçidos de trato, sino de fe y de conçiençia, pagando sus diezmos y azaquees [limosnas] y que cumplen con Allah y ganan buena fama.

Baxo del grado de los mercaderes biben todos los que tratan de mercadurias en bender y comprar, nabegando por el mar y por la tierra, poniendose en peligro: los que hazen abenençias en guisa de mercadurias, sabido el probecho segun biben: tendeeros, traperos, joyeros, espeçieros, boticarios y todos los otros que con su trato y abenençia biben sin engaño, con justo pesso y medida: manteniendo berdad y justiçia, guardando su conçiencia, y temiendo ad Allah salban sus almas.

Baxo del grado de ofiçiales biben todos los que tienen ofiçios que hazen tales cosas de sus manos y las venden con que se mantienen de sus trabajos: todos los ofiçiales de qualquiere generos que sean que ganan de comer sin cargo de conçiencia sirben ad Allah y gobiernan sus cuerpos y salban sus almas.

El grado de maestro debaxo del qual biben todos los maestros de la ley y çunna [tradición], de teologia, filosofia, logica, mediçina y todos los que saben enseñar disçipulos de alguna sabiduria, doctrina y buena arte y enseñamiento, en lo qual ganan su mantenimiento y salbaçion para sus almas.

Baxo del grado de disçipulo biben todos los que aprenden leyes ó artes con maestros, y todo aquello es doctrina birtuossa, la qual continuando salban sus almas.

El estado de labradores se dizen billanos: en el qual grado biben cabadores, acarreadores, molineros, labradores, ganapanes que lleban cargas á cuestas de unas tiendas á otras y hazen lo que les mandan en qualquiera cosa; peones, ortelanos que todos biben usando corporalmente ofiçios baxos y menospreçiados, los quales continuando á buen fin sin mal engaño se mantienen y se salban. El grado de mugeres es que biben en su estado toda muger dueña ó donzella, moça ó casada, biuda ó sierba, y todos los otros grados femeniles y mugeriles: cada una segun su grado, biben en graçia de Allah taale, siendo leales con él y sus criaturas, y salban sus almas.

Baxo del grado del baldio biben todas las otras personas que son fuera de los nombrados, en cuyos biçios biben y abitan los corsarios, ladrones, robadores, biolentadores, rufianes, malas hembras, hechizeros, adebinos y todos los otros que biben cara con dos en- 
besses, bistiendo un abito y usando de otro, traydores, traspassadores, mintrossos, ymbidiossos, maliçiossos, sospechossos, blasfemos, embriagos, consentidores de pecados luxuriossos, biçiossos, ereges, foragidos, apartados de la bida birtuossa que no hazen cosa buena por si ni sus miembros, sierbos del cuerpo universal de la espeçie umana, compañeros y pobladores de la carçel y de la horca, y al fin del ynfierno: exemplo dado por Allah á las criaturas, sobre lo qual los buenos deben esforçarse procurando creçer en birtudes y los malos en refrenamiento de sus biçios.

Conocer debrian los buenos que los tiempos [son] perdidos, quando de sus artes no ussan, ni cumplen con Allah ni con sus deudos ni çunnas del açala [oración] y sus encomiendas, y que son obligados en aquel punto que desto cesan á entrar de nuevo en la carrera, y que si no lo fazen son contados en el grado de los baldios, nobadores, y traspassadores de las obras birtuossas. Por lo qual á los unos y á los otros combiene aborrecer los biçios y hazer berdadera repintencia, y seguir la birtud, apartandose de los biçios y pecados, y desta suerte alcançarán la felicidad de la gloria perdurable por el bien abenturado $m h d$. [Muhammad] çalle Allahu aleyhi guaçalam [bendígale Dios y le salve] y con los de su aluma [comunidad, pueblo] que fueron buenos y siguieron las birtudes para siempre jamas. Y las loores son ad Allah, criador de todas las cossas, en quien todo huelgo cumplido consiste. Plegue á su santo poder darnos su graçia para que hagamos cossas con las quales él sea serbido y pagado, y nos defienda por su infinito poder de hazer cossas malas con que se dessirba y nos dé gloria perdurable. Emen ye Allah rabbi yl aalamina [Amen, oh, Allah señor de los mundos].

\title{
APÉNDICE II
}

\section{Breve Compendio Mancebo de Arévalo y Baray de Reminyo ${ }^{35}$}

\author{
Capítulo terçero de los grados en que el mundo se gobierna
}

Los grados o estados en que el mundo se gobierna son doze, de los cuales sacan los nahues [comentadores del Corán] grande número de doctrina, y cada uno destos grados o estados contiene en sí dibersos costumbres, tratos y bibiendas, usos y exercicios, de los cuales, usando cada uno en su tiempo y lugar segun debe, acordando, sirbiendo y amando a su criador, serán dignos de ser loados [234v] dexando aparte el dozeno y último grado, del cual haremos mençión en su lugar y tiempo, los cuales grados son lols sig[u]ientes: el grado de alhalïfa [califa], el grado de mufti [jurisconsulto], el grado de caudillo, el grado de religioso, el grado de çiudadano, el grado de mercaderes, el grado de ministro, el grado de maestro, el grado de diçipulo, el grado de labrador, el grado de muger, el grado de baldíos.

El primero grado es el estado de alhalīfa, adelantado mayor de Allah, çubhānahu [alabado sea], y su regla deçiende de los annabíes [profetas], y su estado de los más nobles de la criazón del mundo, por donde no pude faltarle la nobleza. No cabe su fecho a par de ningún fecho terrestre, por la asistençia que le terrestó [sic] Allah. A él es debido todo omenage y obediençia

35. L.P. HARVEY, «The Thirteen Articles...», pp. 25-29. He definido los vocablos árabes entre corchetes. 
por la acomanda que led dio Allah de la conquista y defensa del addīn del alislem [religión del Islam], del cual grado deçienden y toman origen los prínçipes, reyes, prebostes y todos los demás que rigen y cobiernan [sic], administran justiçia del segundo mandamiento relatada, a todos los cuales toca ebitar ira, soberbia y enojo, juçgando con toda derechura, y tomando su derecho justo, serán dignos de alabança en este mundo y mereçedores de gloria perdurable.

El segundo grado es estado de muftī, que es protector de la ley y çunna, y su juiçio es absoluto. Puede sobre crimen de ley castigar, matar y conçeder decretos y otras preeminençias de la ley y çunna. Es pilar de nuestro onrado alquren [Corán], así como el alhalīfa, baxo del cual estado [235r] son los nahues, que estos son los ordenadores, xarhadores [exegetas] y declaradores del onrado alquren, de donde toman gobierno las cuatro reglas. Los 'alimes [sabios] son los que sirben mesquidas de aljama ${ }^{c}$ as [mezquitas de comunidades], adelantados por serbicio de Allah, examinados por Melik y sus tenentarios. No pueden ser oprimidos sino en ciertas cosas estrabagantes reserbadas al summo alhalifado, y todos son sugetos al muftì. Baxo deste estado biben todos los alfaquíes [expertos en ley musulmana], legistas, sabidores, cronistas, predicadores, declaradores, disponedores, administradores, consegeros, lógicos, filósofos, teólogos y todos los otros letrados que an de ser súbditos por ley, que cada uno dellos tiene lectura en su grado, y arte de çiençia de ordenar, cumplir y determinar las cosas de la justiçia temporal y espiritual, de lo cual, usando cada uno con efecto, claredad y birtud, serán mereçedores del bien berdadero, perdurablemente.

El grado terçero es de caudillo, segunda persona del alhalīfa, diputado para gobierno de toda la gente de g[u]erra, el cual puede con absoluta hazer y deshazer, subir y baxar cargos, castigar, mandar y bedar en las batallas, trabadas y reñidas. Es absoluto para todo lo que su pareçer le conbida, y quedando después de la batalla sugeto a su alhalīfa, baxo del cual grado o estado biben capitanes, qadis [jueces], caballeros, hijos de algo y de linages conoçidos, gentiles ombres que usan y biben de armas y caballerías o tratos birtuosas costumbres, lealtad y franqueça, en lo que está a su cargo, y gobernar a conserbaçión y defensa de bien común, a fin de lo cual fueron criados.

El grado de religioso: este es estado podiçial, el más feliçe para el alma, en el cual estado biben todo creyente bienabenturado que mantiene y g[u]arda la ley, ábito y comunidad del aljama ${ }^{c} a$, toda ermandad y concordia. Ay unos de más religión que otros, en cuanto son apartados de los biçios, así como son ayunadores, limosneros, oraçioneros, y todos los que hazen bida rabidal [eremitas]. Todos éstos son acotados por débiles para la g[u]erra, ni pueden ser oprimidos para tales exerçiçios, baxo de las cuales bibiendas sustentan sus cuerpos y salban sus almas.

El grado quinto es estado de çiudadano, en el cual biben todos aquellos que son sustentados de sus rentas de eredades sin trabajo de sus manos ni ningún género de trato. Son ombres onrados de fe y de conçiençia, pagando sus dieçmos, acudiendo con sus algos a la defensa del addīn, y a toda neçesidad y cuita aljamacal. A éstos llaman los nahues fiadores situados, acreedores firmes, éstos son en segundo grado y posesión de mayoría y onra primitiba y justa. Pagando sus azzakees [limosnas, diezmos], cumplen con Allah y salban sus almas.

El grado de mercaderes biben todos que tratan de mercaderías [236r] compras y bentas, y son nabegantes por mar y tierra, poniendo en peligro sus personas y mercaderías, haçiendo abenençias justas, como son tenderos, traperos, joyeros, espeçieros, boticarios, y todos los otros que con su çierto trato y abenençia biben sin engaño, con justo peso y cumplida mesura, manteniendo berdad y g[u]ardando sus conçiençias, temen ad Allah y $\mathrm{g}[\mathrm{u}]$ ardan sus almas. 
El sétimo grado es estado de ofiçiales, en el cual biben todos aquellos que tienen ofiçios, y con las labores que hazen de sus manos, bendiéndolas, sacan sustento para sus cuerpos, de lo cual se mantiene todo ofiçial con trabajo justo, gobiernan sus cuerpos y salban sus almas.

El grado de maestro es el estado octabo. En él biben todos los maestros y enseñadores de la ley y çunna, y todas las demas artes y çiençias, y todos los que saben enseñar diçípulos de çiençia o arte. Este grado toca a los padres de familias en enseñar a sus hijos y súbditos, todos los cuales, enseñando, gobernando y doctrinando, ganan sustento corporal y espiritual.

El grado nobeno es estado de diçípulo. En este grado biben todos los que aprenden leyes, çiençias o artes, ofiçios con maestros, que todo es dotrina y enseñança buena, los cuales, continuando la birtud y la çiençia de su arte, gobiernan sus cuerppos y sus almas.

El grado dezeno es grado de labradores, que se llaman billanos, cabadores, molineros, labradores, ganapanes que lieban cargas a cuestas de unas partes a otras, y hazen lo que les mandan, alquiladores, peones, ortelanos, que todos biben usando sus ofiçios baxos y menospreçiados. Destos son muy açeptas de Allah sus buenas obras, por la menoscabança de sus ofiçios y bibiendas, y sus minçiones son muy haleles [lícitas], y continuando a buen fin, y sin engaño, de que se mantienen y salban sus almas.

El onzeno grado es estado de mugeres, en el cual bibe todo ábito de muger, dueña, donzella, moça, biuda, sierba y niña, y todos los otros grados femeniles y mugeriles que biben en graçia digna, siendo leal ad Allah y a toda criatura, biben en buena fama onradas y salban sus almas.

El dozeno y último grado es estado de baldíos, en el cual biben todas las otras pesonas que son fuera de los nombrados, como son corsarios, ladrones, robadores, biolentos, rufianes, malas hembras, hegizeros, adebinos, y todos los que biben cara con dos fazes, que bisten un ábito y usan otro, dizen uno y obran otro, traidores, traspasadores, mintorosos, enbidiosos, maliçiosos, sopechosos, luxuriosos, erejes encartados y fuera echados de la birtuosa bida, que no hazen cosa [236r] buena por sí ni por otro, seg[u]idores de sus apetitos, sustentando solamente los biçios del cuerpo de la espeçia unibersal y umana, pobladores de la cárçel y de la horca y del infierno, de lo cual debe tomar exemplo toda criatura, y conoçer deberían los tales su mal estado, y considerar los buenos que los tiempos perdidos cuando de sus artes no usan, ni cumplen con Allah ni con sus deudos de la ley y çunna, en aquel punto son puestos en el número y grado destos baldíos, robadores y transgresores, por lo cual los unos y los otros deben aborreçer los tales biçios y hazer berdaderas apenidençias, por las cuales alcançarán la feliçidad de la gloria perdurable. 


\section{APÉNDICE III}

\section{Sumario del Mancebo de Arévalo ${ }^{36}$ \\ Capítulo del estado de alhalifa [califa] y cómo es debido conocer su autoridad y acatar su hecho y nombre}

Es debido a todo muslim [musulmán] por lejano que sea, tener un aliento de fe hacia el alhalifa y así lo manda nuestro honrado Alcorán. Porque alhalifa está en lugar de Allāh en derecho y en hecho, y no puede derogar la Guerra Santa por ninguna vía. Y manda Allāh sea de todo muslim acatado tanto en ausencia como en presencia; y esto por la asistencia que le prestó Allāh çubḥā-nahu [ensalzado sea\}.

Y así mismo es la persona del alhalifa en gran obligación para todo muslim, no cabe su hecho a par de ninguno. A él es debido todo homenaje, a él es debido todo el provecho de la obediencia, a él es debido todo el encanto de nuestros diezmos y así mismo el azzakā [limosna] adeudado por nuestro honrado Alcorán.

Como dijo 'Umar bey: La gran joya a gran señor pertenece porque su distribución es en sufragio de todos y no puede caer en destino. [125v] Y quien no obedece su mandato es digno de muerte; y el preboste o rey que tomare pleitesía con alhalifa pues allá irán al infierno. Y no pasan los decretos de ley si no los asiste alhalifa o su presidente y es su conquista justa contra todo decretante de ley o xara [ley civil] y contra toda rebeldía que se haga contra su real estado. Y quien le niega sus diezmos será partícipe del infierno.

De modo que todo el provecho [o ventaja] de nuestra posibilidad es conocer lo que manda nuestro honrado Alcorán porque hay mucho movimiento en breves dichos y todo abunda y nos consta, y así mismo esta conspiración alhalifal.

Y quien diga denuesto contra alhalifa, dice contra Su Divina Bondad pues no repudie nadie lo sobredicho porque es obligación de todo muslim.

\section{Capítulo donde se declara el estado de muftí [jurisconsulto] y cómo todo muslim es obligado a conocer su acatamiento}

El muftí es protector de la ley y su juicio es absoluto y puede, sobre crimen de ley, castigar y matar y conceder decretos y otras preminencias de ley sunnal [de acuerdo a la tradición]. Es pilar de nuestro honrado Alcorán, así como alhalifa del addīn [religión]; no puede nadie conceder en los cabildos nahuales [relativos a los exegetas] sin decreto de muftí.

Esta preeminencia es muy honrosa y toca obedecer a todo cultivador de ley y a todo elector por idóneo que sea -hasta nuestro Mālik [tradicionista y creador del rito maliquí] es súbdito suyo- $\mathrm{y}$ es reformador de todos los cabildos.

36. Véase Sumario de la relación y ejercicio espiritual..., edición, estudio lingüístico y glosario por Gregorio Fonseca Antuña, pp. 265-269. He modernizado el texto y definido entre corchetes vocablos árabes y confusos. He intentado preservar en parte el estilo original. 
No puede usar de achaque ni de ninguna prontitud y es temido por todo delito santimonial [relativo a los santos].

Es en su procedimiento sobrevenir a todo lo grave de la ley y sunna, como detractor de xara y ley, tiene en los nahuis más sabios que hay en toda la regla de Malik. [126v] De este juicio del muftí no hay apelación.

Son tantos los réditos de esta regla que no hay [lugar] para los tafsirar [comentar] si no rogar por la observanza de estos estados, a lo cual estamos obligados todos los muslimes so pena de juro, que esto ya nos será demandado como siervos de Allāh çubhạanahu.

\section{Capítulo del estado podiçial [relativo al poderío]}

Este es el de los al abidās [recogidos o amparados] y otras cualesquiere personas recogidas y amparadas. De todos los estados, éste es el más feliz para el alma.

Dijo Katādatā: ¡Ah, tan buen perdón que verá quien dejare la pleitesía de este mundo!

Dijo 'Umar bey: ¡Oh, siervos de Allāh, yo os consigno al Paraíso a todos los capacitados espiritualmente de anniya [buena voluntad] y obra, aquellos que haréis desdén de este mundo, porque la vida es para el otro mundo.

Dijo Almurabāci: ¡Oh, cómo pasamos los piélagos de esta vida sin darnos cuenta de lo que habemos de ser, y cómo habemos de pasar por la dormida mayor, y nos han de dar el parabién de nuestro despertar!

Plegue a Su Divina Bondad inmensa que nos dé tal perdón que pongamos açubd [ampara] para cuando sople Içrafîl en su trompeta, que dicen los nahuis que dará tan fuerte toque, que no quedará alcars [trono] sin estremecerse y moverse su centro, y quien más se retorcerá será la tierra que pisaron los hijos de Adán,

Bien sintió Almurabāci lo que dijo, pues lloro el rey de Córdoba toda la luna de dulhiganante [último mes del calendario musulmán, mes de la peregrinación a Meca], tan buena para los aptos y salihas [piadosos, eremitas]. A éstos llaman llorosos espirituales, que dan luz con sus hechos.

Dice 'Umar bey: Si los hijos de Adán tasasen sus alhulas [actos profanos] y dormidas [en sentido espiritual] y no dejasen envejecer [127v] sus gravedades [en este contexto, malos actos], serían salihas con los buenos y los santos.

Como dice la Mora de Úbeda: No hay cosa más amada que la salvación: de todos muy adorada y de pocos obrada.

Pues no puede ninguno sin plañida [lloro] dar fragancia a su alma porque ya nos enseñó Adán con cuarenta años de alqafara [penitencia] hasta que los atajó Gabriel [el ángel] por mandado de Allāh y lo amahó [perdonó, borró sus pecados] Gabriel de parte de Allāh, consignándole al estado al arssikal [del trono de Dios] ${ }^{37}$.

37. De aquí en adelante el texto aborda otros asuntos de doctrina y ritual no relacionados con el tema de los estados. 


\section{APÉNDICE IV}

\section{Capítulo que trata de los estados y sus conocimientos Tafsira del Mancebo de Arévalo ${ }^{38}$}

Dice Muhammad Algacel que es propiedad de discretos examinar todos los consejos y por ligera creencia no probar lo que parece dudoso, sopesar la creencia por la honra de Allāh y por la suya propia y para ejemplo de la comunidad, porque no es verdad todo lo que tiene semejanza de verdad. Pues dice más: El pensamiento el sabio nunca se aparta de lo que puede acaeceer, siempre con recelo de su buena fama y honra teniendo siempre en la memoria las obligaciones nahuales [propias de los exegetas del Corán]. Que la primera obligación es la que se debe a su Creador, y la segunda a sus padres, y la tercera a su aljamaca [comunidad de fieles], y la cuarta a sus parientes, y la quinta a sus hijos, y la sexta a los pobres, y la séptima a los aflijidos, y la octava a los animales provechosos. $Y$ para todo esto es menester audacia porque el mundo da lo peor de su casa y naturaleza, cría las cosas a manera de contienda y a modo de pleitesía, contrario uno de otro y por esto es bueno que cada uno roa las cortezas de los [hombres] constructivos y de sus dichos provechosos, de aquellos que por sus claros ingenios espirituales merecieron ser honrados y aprobados. Con lo poco que saquemos [de sus ejemplos] colmaremos nuestra escasa diligencia. Más dicen: ${ }^{* * 39} \mathrm{Sin}$ lid ni ofensión ninguna cosa engendró la naturaleza que es madre de todas las cosas, las cuales dan testimonio en su pronunciación que las estrellas se encuentran en el firmamento de los cielos; adversos elementos unos a otros se rompen, estremecen las tierras, ondean las mares, el aire se sacude, suenan sus llamas, los vientos entre sí traen perpetua guerra, los tiempos contienden y litigan entre sí, cada uno y todos contra nosotros. El verano vemos que nos aqueja con calor demasiado, el invierno con frío y asperezas; así que estos que nos parece revolución temporal, esto que nos sostenemos, esto que nos criamos y vivimos si comienza a ensoberbecerse más de lo acostumbrado no es sino guerra. Y cuánto se ha de temer manifiéstase por los grandes terremotos y torbellinos, por los naufragios e incendios, así celestiales como terrenales; por la fuerza de los aguaduchos, por el retumbe de los truenos, por el ímpetu de los rayos; aquellos cursos y recursos de las nubes de cuyos abiertos movimientos para saber la secreta causa de donde proceden, no es menor la disensión de las escuelas que las turbaciones de todos los que distinguen tales secretos. Pues entre los animales ninguno hay en su género: no carecen de guerra. Estrellas, peces, aves y los demás terrestes animales ${ }^{* *}$, hasta los pensamientos guerrean entre los jaleqados [creados] y discurren las pleitesías y guerras, las artes y los engaños contra los cuerpos y las almas y en toda cosa parecerá lo mismo. Y los estados en que vivimos guerrean unos contra otros por falta de conocimiento. Los bajos estados por llegar y los altos por mandar traen entre sí la guerra heredada de unos para usurpar a otros hasta

38. Tomado de María Teresa NARVÁEz, El Mancebo de Arévalo, pp. 295-298. He modernizado el texto y definido entre corchetes vocablos árabes o confusos. He intentado conservar en lo posible el estilo original.

39. El pasaje del Mancebo marcado con ** está tomado casi al pie la letra del prólogo a La Celestina de Fernando de Rojas. Éste a su vez lo tradujo del De remediis utriusque fortunae de Petrarca. Véase María Teresa NARVÁEZ, «El Mancebo de Arévalo, lector morisco...». 
que vean las señales juicio. Dijo 'Umar bey: ¡Oh, si los hijos de Adán conociesen su estado de rico o pobre, de grande o menor! Dijo más: que este es el más alto conocimiento después del conocimiento del Creador y de sus mandamientos. Dijo más: que los estados que son en mayores comodidades son los que atañen al mundo y al alma; y por esta vía los que más dañan son los más altos, grado tras grado y los más cercanos a la reparación del alma son los bajos estados, comenzando por los annūtas [afeminados] y así grado tras grado. Dijo más: En todos los grados hay salvación y constreñida [¿arrepentimiento?] para los de buena consciencia. Y la mayor constreñida es la del estado mayor porque es sometido a la Suma Bondad y a los otros grados en grado mayor. Y por eso dijo el annabī [Profeta] ș $\mathrm{s}^{\mathrm{m}}$ [abreviatura para "Bendígale Dios y le salve"] a los de su compaña: No queráis desear estados altos, que son grandes sus contornadas [reveses]. Más dijo: Tendréis seguridad cada uno con su avenida [acuerdo o ajuste] y no denostéis vuestro hado y estado porque denostando vuestra avenida, denostáis a Allāh sbḥnh [abreviatura para "alabado sea Dios"] y porque los estados y grados son departidos cada uno de por sí. Y aquí no se departen más allá de que hay seguridad en todos si los adornas de buena contemplación. Y en cualquiera de ellos sea vuestro contento perdurable, que esto es vuestra primera apariencia, amando a todo muslim [musulmán], con reconocimientos usados como lo son: hablas amorosas y arrak ${ }^{c}$ osas [propias de los movimientos rituales de la oración] y otros usos de los antiguos; que aún hay algunas reglas de ellos a manera de socorro, haciendo presentes alrrahmosos [misericordiosos] de poca cantidad y de mucha maduración para la conveniencia de la gente. Porque donde hay o debe haber agradecimiento no puede haber remordimiento de lo bueno que ha de vencer a lo malo, y también tornarse a Allāh sbḥnh. Y por eso dijo Katādatā: Más cerca está lo bueno de lo bueno que lo malo de lo malo. Pues amad los socorros a menesterosos y las datūas [dádivas] graciosas, placenteras, ke todo es amado por Allāh. Y dijo más Katādatā: La obligación antepuesta es alabada y amada por Allāh y por las gentes. Y esto se colige por la sihāba [compañeros del profeta Mahoma que establecen la tradición]. Un judío quería matar a 'Umar y le acompañaba: todos estaban muy tristes porque era tiempo de hambre. Y 'Umar le dio como presente treinta dátiles y cuando el judío vio tal gesto, se sacó un puñal que llevaba bajo el manto y lanzólo fuera. Y después le confesó cómo había sido su voluntad matarlo y enseguida se hizo muslim y fue amado por la sihāba. Pues hechos como estos son innumerables, no dejen los muslimes de hacer tal bendición hasta su muerte. Dijo Katādatā: Haz guerra contra tu carne y no te canses y descansará tu alma en los duelos de tus restauraciones [restituciones] y alcadabes [tormentos]. Tanto en esta vida como en el otro mundo no hay libertades ni ruegos de aflijidos hasta que hayas redimido tus pecados como lo manda Allāh por su honrado Alcorán. Pues no seas tayuh [vocablo no identificado] en tu vida, sé desvelado para contigo mismo y para todos, serás de tu desvela [?] y serás desvelado, como dijo Zacarías: "Si das a todos, todos te darán a ti".

No juntes lo malo con lo bueno. Y no uses de hablas vanas ni graciosas de modo que puedas causar alguna deshonestidad, que es un uso vil y trae menoscabo de obra y honra. $Y$ quien hace eso no puede ser adelantado en el-așsala [oración] ni pasa por alwalī [el que presenta a la novia en la boda] justo ni tiene acto a sus años [?] hasta su vista de luna sino para un tercero, y si es idóneo de letras no puede fașalar [¿de fașl, excelencia?] sino reprochadamente y queda desprovisto de todas las honras hasta que sea conocida su enmienda por su recato y contrato [?]. Y pasa su testimonio en crimen y testamentos de difuntos y puede, en falta de alimām [el que dirige la oración en la mezquita], atender a las juras si tiene baastantes letras [es letrado] y para tales cosas que no son honradas. La contratación más honrosa es seguir por la vía de los que tratan por la ley y la sunna [tradición]. Y la segunda los belicosos 
de la guerra, que están acostumbrados a hablar de armas. El tercer poderío es el trato de los que guardan [prohíben, evitan] las denostanzas contra padres y ancianos; y el cuarto es en casos perseverantes [?]. Y el quinto es la contratación de compras y ventas justas y no sigas las que no son nombradas por su trato deshonesto. Porque dijo Al-Hasan: Toda la vida es llena de caminos buenos y de caminos malos y de alqafaras [penitencias] grandes y pequeñas y rellegan [?] de pecados oscuros, pequeños y grandes. Dijo más: que hay caminos de recuerdo y caminos de descuido. Dijo más, que hay caminos que traen penitencias y otros que se las llevan. Y por esta causa hay muchos que pintan estos caminos en paños para la soledad del olvido. Y por eso dijo 'Umar bey, admirado: ¡Oh, hijos de Adán, las buenas vías serán pagadas y las malas vías serán pagadas. Bien que cifró este alimām para los negligentes de estas vías y caminos. Dicen los nahūes [exegetas] que si descendiese a este alcarsse [trono, en este caso, plano terrestre] una centella de la claridad de aquella luz beatífica del al arsse soberano donde Su Bondad manifestó las cosas incomprensibles, que la tal vislumbre no impediría cosa a vuestros ojos por delante ni por detrás, tanto con ampara como sin ella, tanto lejos como cerca, tanto lo mínimo como lo grande, ni aunque fuese un átomo a sol saliente y otro a sol poniente. De tal suerte que la luz de nuestros ojos penetraría como la luz del sol de este alcarsse. Dice el honrado Alcorán: Alcanzaréis esta luz, no seáis negligentes, obrad según el Alcorán y habréis luz y descanso y holgura en vuestras almas.

\section{RESUMEN}

Se explora el tema de los estados en la literatura medieval española y en el Islam tardío español. Un análisis de cómo aborda este tema la obra aljamiada (escrita en castellano con caracteres árabes) y clandestina del Mancebo de Arévalo (s. XVI) arroja luz sobre la "hibridez cultural" de España. El Mancebo de Arévalo "adapta" los estados según su predecesor, el alfaquí mudéjar Iça Gidelli e ilustra su comentario con citas del prólogo de La Celestina. La comparación entre el tratamiento del tema (con connotaciones sociopolíticas y religiosas en el caso islámico) entre cristianos y musulmanes (sean mudéjares o moriscos) nos revela cómo ambas comunidades intentan establecer un orden ideal ante la realidad caótica que les ha tocado vivir.

Palabras clave: Mancebo de Arévalo, Iça Gidelli, estados, orden social.

\section{ABSTRACT}

It explores the motive of the "states" (estados) both in Spanish medieval christian literature and in late Muslim Spanish literature. The latter analysis of the abovementioned motive includes the clandestine aljamiado (written in Castilian using the Arabic alphabet) works of the Mancebo de Arévalo (XVIth century) which demonstrates Spanish cultural "hibridism" or multiculturalism. El Mancebo uses both his predecesor, the mudéjar afaquí Iça Gidelli and parts of La Celestina's prologue to illustrate his commentaries. The comparison between christians and muslims (including both mudéjares and moriscos) 
treatment of the sociopolitical (and religious in the Islamic approach) motive of the "states" shows that all communities were struggling to establish an ideal order among the chaotic social reality in which they were living.

Key words: Mancebo de Arévalo, Iça Gidelli, "states", social order. 